\title{
Proposing A Systems Vision of Knowledge Management in Emergency Care
}

\author{
John S. Edwards, Matthew Hall and Duncan Shaw, Aston Business School
}

\begin{abstract}
This paper makes a case for taking a systems view of knowledge management within health care provision, concentrating on the emergency care process in the UK National Health Service. It draws upon research in two case-study organisations (a hospital and an ambulance service). The case-study organisations appear to be approaching knowledge (and information) management in a somewhat fragmented way. They are trying to think more holistically but (perhaps) because of the ways their organisations and their work are structured, they cannot "see" the whole of the care process. The paper explores the complexity of knowledge management in emergency health care and draws the distinction for knowledge management between managing local and operational knowledge, and global and clinical knowledge.
\end{abstract}

Key words: health, hospitals, ambulance services, knowledge management, systems, problem structuring methods.

\section{Introduction}

The government-funded National Health Service (NHS) provides the majority of health care in the UK. It comprises many interacting organisations of different types, such as doctors' surgeries, hospitals and ambulance services. Provision of care to a patient during any particular "episode" may involve several of these organisations, operating in a form of supply chain, or rather a "care chain". Clearly with a number of organisations concerned, there is a danger of fragmentation or compartmentalisation in the planning and delivery of patient care.

This paper takes as its starting-point the desirability of a systemic and process based view, not just within a single organisation, but across all the organisational units involved in providing a given type of care for a patient. This process integration across different organisations is now very much advocated in other sectors of industry ${ }^{1,2}$. A patient-centred view is important, since the patients' perspective does not always match with those of the health care professionals, as a survey ${ }^{3}$ of 2000 patients in the USA revealed. The need for a 
patient-centred, process-orientated view has been accepted in some parts of the NHS, for example in the design of care pathways or treatment pathways involving different health care professions. However, the care pathways only cover what happens once the appropriate treatment has been determined, and are at a relatively high level. Note that a number of organisations in the UK NHS have taken a more detailed process view within the boundaries of their own organisation, for example Leicester Royal Infirmary ${ }^{4}$ and St. James's Hospital Leeds ${ }^{5}$.

The paper draws upon research in two case-study organisations within the NHS. One is a hospital, and the other an ambulance service. They will be referred to as Hospital and Ambulance throughout this paper, to maintain their anonymity. These case studies are used to argue for the importance of taking a systems view of knowledge management (KM) within health care provision. The case-study organisations appear to be approaching KM in a fragmented way. They are trying to think more widely towards the 'whole' but (perhaps) because of the ways their organisations and their work are structured, they cannot see the whole of the process. This paper helps in taking forward an understanding of where the process boundaries are from a knowledge management perspective in the NHS. There is a particular emphasis in the paper on the actual and potential roles of information and communication technologies (ICT) in this process. This stems from the interests of the two case-study organisations. ICT is also very high on the NHS agenda nationally at the time of writing ${ }^{6}$.

Through the case studies, the paper offers insight and help to understand how a 'systems vision' might improve knowledge management in the NHS. We concentrate exclusively on what we term the 'emergency care' process in the NHS, and on the implications of this 'process' for how the organisations approach knowledge management. The term emergency care is used in an effort to avoid using standard NHS terminology, which in some aspects reinforces a bounded view. Its meaning in this paper is "a patient urgently and unexpectedly requires advanced medical attention".

The paper is structured as follows. We begin by reviewing the literature on knowledge management, processes and systems, and their relevance to health care. This includes consideration of ICT in knowledge management. We go on to describe the research methodology, including the workshop methodology used and the approach to data collection 
and analysis. Results from the two cases, Hospital and Ambulance are presented next, followed by analysis and discussion. In this we distinguish two kinds of foci for knowledge management (local and operational knowledge, and global and clinical knowledge). Finally we offer the limitations of this work, suggestions for future research, and our conclusions.

\section{Knowledge management, processes and systems}

There is no generally agreed definition of knowledge management to be found in the literature. For the purposes of this paper, we offer the following: "supporting and achieving the creation, sharing, retention, refinement, and use of knowledge (generally in an organisational context)". This was used in structuring the workshops and analysing the data collected. Frequently, information is an essential input to a knowledge management activity, especially in an organisational context. Consideration of a knowledge management system (whether ICT-based or not) thus also normally requires consideration of information and its management. However, knowledge management is more than information management, because of the vital additional element of the "knower".

Our further discussion in this section concentrates on the role of processes and systems in knowledge management. The perspective taken in this paper is that the notions of systems and processes are complementary to each other. Both imply an holistic view, and the concept of purposeful activity directed towards some form of customer(s) or indeed victim(s). Given the organisational setting of most knowledge management, the potential for a systems view to offer a holistic approach to knowledge management seems clear. However, most reported approaches to knowledge management do not take such an approach. For example, Rubenstein-Montano et $\mathrm{al}^{7}$ also advocate a systems approach to KM in their extensive study, and analyse no fewer than 26 frameworks from the literature. Their conclusion is that none of these KM frameworks meet the systemic requirements fully, in particular the lack of allowance for double-loop learning, as proposed originally by Argyris and Schön ${ }^{8}$.

More specific examples of systems or process thinking in knowledge management may be found, but relatively rarely. For example, Cuthbertson and Farrington ${ }^{9}$ use Soft Systems Methodology (SSM) in KM strategy formulation, while Ferrari et al ${ }^{10}$ discuss using SSM for $\mathrm{KM}$ in a Brazilian company. Al-Karaghouli et $\mathrm{al}^{11}$, on the other hand, use the SSM technique of rich pictures to understand knowledge requirements, but not the rest of SSM. 
Senge's work on systems thinking and organisational learning ${ }^{12}$ is often cited in the knowledge management literature, but the emphasis in the citations is often more on learning than on systems. Another systems view is seen in the collection of work written from a sociotechnical systems perspective edited by Coakes et al ${ }^{13}$.

Given the relative rarity of systems approaches to knowledge management overall, it is not surprising that there are few specific examples of a systems or process approach to knowledge management in health care reported in the literature. We have found three. The first is by Reuthe \& Allee ${ }^{14}$, who discuss a team-based approach to providing health care, using an example of "birthing" (maternity) provision. This is designed as a patient-centred process, with the emphasis on the patient and her history rather than the specific "episode". The second is the work by Desouza ${ }^{15}$, who offers a process model for KM in hospitals. Our paper differs from both of these in that it goes beyond the boundaries of a single organisation in the health care process. The most similar to our work is the third paper, by Newell et al ${ }^{16}$. This reports a knowledge management project concerning cataract surgery. The project implemented a re-designed process for the steps prior to the surgery itself, which changed the roles of different professional groups. The authors describe their approach as holistic, in that multiple professional groups worked together to design the new system, but the project did not explicitly take a systems approach, as we or Rubenstein-Montano ${ }^{7}$ would characterise one.

In view of the paucity of references to knowledge management, systems and health care, we now go on to review the literature on systems in health care and knowledge management in health care separately.

\section{Systems in health care}

Beyond the context of knowledge management, the idea of taking a systems view of health care organisations is not a novel one. Indeed, various parts of the UK NHS have served as examples in the core texts on Soft Systems Methodology. These include community medicine in East Berkshire Health Authority ${ }^{17,18}$ and information systems in Huddersfield Royal Infirmary, the Royal Victoria Infirmary and Hexham General hospital, amongst others ${ }^{19}$. Lehaney, Clarke and Paul describe ${ }^{20}$ and evaluate ${ }^{21}$ the use of SSM in the construction of simulation models for a hospital outpatient department. Batalden and Splaine ${ }^{22}$ also advocate taking a process view of health care provision, with an emphasis on what they call the 
microsystems level. The microsystem is the group of people actually giving care to an individual patient.

\section{Knowledge management in health care}

The importance of knowledge management has been well recognised in many parts of the health sector. At the most general level, van Beveren ${ }^{23}$ studied the knowledge management needs of a public health care system in Australia. He concluded that specific models and techniques were needed for knowledge management in the public sector in general, and the health care sector in particular. The whole of the February 2001 issue of the journal Topics in Health Information Management (Volume 21, issue 3) was also devoted to knowledge management. Most of the articles were visions of future issues and possibilities rather than reports of completed projects.

There are also more specific examples. A system that checks drug prescriptions given by hospital doctors in Boston, USA was devised by Davenport \& Glaser ${ }^{24,25}$. Like us, Pedersen and Larsen ${ }^{26}$ look at inter-organisational KM, but their focus is on decision support, and in administration not treatment.

Within the UK NHS, the changing relationship between clinicians and managers has been a significant issue for many years. Ashburner and Fitzgerald ${ }^{27}$ have looked at how these changes affect the management of expertise. The NHS National Electronic Library for Health offers a whole web site on KM (http://www.nelh.nhs.uk/knowledge_management/km1/nhs.asp\#knowledge, accessed 10 February 2004).

KM practitioners more generally also see health as an important application area. For example, Hansen et al. ${ }^{28}$ included a health care provider as one of the case studies in their widely cited paper introducing the concept of codification and personalization strategies for knowledge management.

\section{ICT and knowledge management in health care}

ICT merits specific consideration because it was the focus of interest in both of our case study organisations. The role of ICT in knowledge management has been the source of much controversy in the literature. A complete range of positions may be found from that of Carter 
${ }^{29}$, who sees technology as key to knowledge management, to that of Scarbrough and Swan ${ }^{30}$, who see ICT as a minor issue compared to aspects such as leadership and motivation. Earl ${ }^{31}$ gives a good discussion of various different types of KM strategy, and the different relevance of ICT to each of them. Alavi and Leidner ${ }^{32}$ review the state of the art of the use of ICT in $\mathrm{KM}$, and discuss future research challenges.

There are many articles about specific ICT systems for KM in health care. For example, Forgionne and Kohli ${ }^{33}$ examined the effects of ICT in the form of a management support system on health-care decision-making. Indeed, advanced ICT has been used in health care in many forms for several years, including digital imaging, videoconferencing, results messaging and expert systems ${ }^{34}$. Moreno et al. report a further use of knowledge-based systems in a hospital ${ }^{35}$. Moseley and Mead ${ }^{36}$ also cover expert system based DSS. There are many other similar examples. A rather different one is the work of Standridge and Steward ${ }^{37}$ who use an expert system to help build a simulation model. This is in marked contrast to the use of SSM for the same purpose mentioned earlier.

We now introduce the methodology used to investigate a systems view of knowledge management. This leads to a discussion of the two case studies.

\section{Research methodology}

Data collection on the opinions of NHS staff about knowledge management was based on computer-supported group workshops. One workshop was held for Hospital, and three for Ambulance. (The precise arrangements were the choice of the participating organisations.)

Table 1 shows the major stages in the research methodology, from the initial contact with the organisation through to analysis of data and feedback of results.

\section{TAKE IN TABLE 1 ABOUT HERE}

\section{Journey Making}

The methodology used to structure the group workshops is one that was initially called SODA (Strategic Options Development and Analysis) ${ }^{38}$ and more recently has been renamed Journey Making, a mnemonic for JOint Understanding, Reflection, NEgotiation of strateg $\mathrm{Y}^{39}$. 
An example of its prior use in the health sector is that of Roginski ${ }^{40}$, who used SODA (as it then was) in working with senior management in the NHS.

Journey Making was used because it offers groups a methodology through which they can share their individual views/perspectives/ideas of the situation - effectively surfacing the diversity of views and the complexity of the situation. Through jointly understanding this complexity the participants can individually and collectively reflect on that complexity to broaden and deepen their awareness of the issues. Negotiation is used to explore the legitimacy of the conflicting views and move the group members towards beginning to jointly agree what are the critical issues. Through this process the group begin to identify combinations of actions to tackle the critical issues - essentially building a strategic plan of action.

In terms of the practical arrangements of a Journey Making workshop, each participant has access to a laptop computer which is networked, and running a brainstorming-type software, Group Explorer. In response to a particular prompt about a situation (e.g. "What knowledge management issues face your organisation?"), participants type their views into the laptop (these views can be contributed anonymously). Once participants have finished typing, all the views are shown on a large projection screen using Decision Explorer software. The facilitator assists the participants to cluster the views to make the volume of information (typically as many as 80 views) more manageable. Participants have the opportunity to read other participants' views, expand on them, critique them or identify relationships between them. Extensive group discussion about the views, the clusters, and relationships between the views then follows. (In the map, a relationship between two views is represented as an arrow linking the views.)

The benefits of a computer-supported approach are numerous ${ }^{41}$ and include: providing an environment in which views can be shared anonymously, encouraging a more open sharing of views $^{42}$; more rapid sharing of views through all participants simultaneously sharing ideas ${ }^{43}$; sharing views without being influenced by others, i.e. having your thinking being limited by the ideas from others ${ }^{44}$; flexibility in the presentation of the views enabling participants to play with the layout of the views thus freeing their creativity ${ }^{45}$. 


\section{The workshop agenda}

A Journey Making workshop is divided into a series of sessions, referred to as the agenda. An initial (flexible) agenda was agreed for each workshop - primarily to reassure all parties involved. However, the agenda actually emerged during each workshop - in that it was designed by the participants during the workshop. Each emerging item on each agenda was pursued due to the participants' belief that it would help them to achieve the declared aims of the workshop. The aims of both sets of workshops were very similar and included:

1. To understand what knowledge needs to be harnessed by the knowledge management system;

2. To design effective processes to enable the system to harness knowledge, skills and experience;

3. To consider the barriers to staff using the system;

4. To explore what are the metrics against which the system would be evaluated.

\section{The research data and the analysis}

The primary tangible research output from these workshops were group maps that show the participants' views, and their interrelationships to other views, on a range of issues (see Figure 1). The maps are artefacts of the group discussion that are used by the groups to stimulate and structure their systematic consideration of the issues. As such, in this project the content of the maps was provided and validated by the participants. Thus an initial analysis and validation of the research data was done by participants during the workshop.

\section{TAKE IN FIGURE 1 ABOUT HERE}

The initial constructs of the maps were used to inform more in-depth interpretative postworkshop analysis. For example, the maps were analysed to understand as much as possible about critical issues that were identified in the maps by the participants. This analysis, together with copies of the maps, was fed back as a final report to the workshop sponsor and the participants. This served to validate the analysis and act as further validation of the content of the maps. All recipients were invited to respond to the report.

In addition to the maps, other forms of data were collected to triangulate and enrich the findings from the maps, including: researcher observations of the group members and any side conversations which were not captured in the maps; participant feedback on the process, 
collected through exit questionnaires; and sponsor feedback on the process and the outcome, collected through a post-workshop de-brief. Thus the validation of the analysis of the group discussions was four-fold: the participants; the sponsor; the researchers; the facilitator.

We include extracts from two maps for background (Figures 1 and 2). We do not discuss their detail as the focus of this paper is on the overall direction and context of the discussions, although in places we have used specific quotes (in italics).

These workshops formed part of a continuing programme of knowledge management research using this approach, the first phase results of which are reported in Edwards et al. ${ }^{46}$ The Journey Making approach is highly relevant to knowledge management, because knowledge management activities are to a great extent group activities, validated and legitimised by the group context: see for example Scarbrough ${ }^{47}$ and Newell et al ${ }^{16}$. Note that we have also conducted a workshop for the whole NHS Trust of which Hospital is a part, but this concentrated on management issues, and thus is not described in detail in this paper.

\section{The cases}

\section{Case 1 - Hospital}

The background to the knowledge management system

The challenges and opportunities posed by new information and communication technologies (ICT) are recognised by all stakeholders in the NHS, particularly managers and doctors as they strive to keep up with the ever growing pace of demand on the service. In Hospital, there is an ICT Committee (exact title omitted to preserve anonymity) which has the remit of overseeing the many ongoing projects and initiatives with an ICT focus. One of these is a local patient records system. The NHS Trust to which Hospital is responsible have been considering funding the development and implementation of their own patient record system to network local general practitioners (GPs), two local hospitals within the Trust, and ancillary patient support services, e.g. physiotherapists or dieticians. The aim of such a system is to allow faster and more efficient recording and sharing among users of patient information, which is consolidated in one electronic source. Doctors in this workshop called this an Electronic Patient Record, although it should be noted that this is not quite the same as the national NHS initiative with that name. 


\section{Positioning the workshop}

The workshop was convened in order to help scope the needs and requirements of such a local patient record to support the Hospital's Medical Assessment Unit (MAU). Staff in MAU deemed it particularly important for MAU to have an ICT system, as the history accompanying patients arriving at MAU, even though referred by their GP, is "often extremely sketchy and inaccurate. It mostly consists of a scribbled, illegible note and a list of drugs. We sometimes (seldom) get a printed history." Preceding the workshop there was also a realisation in Hospital's management of the need to change from the existing paper-based system of patient records. Their motivation to change was driven by repeated failures of the paper-based system, for example, missing records, unreadable handwriting, and loss of time in transferring records from the GP to the Hospital.

\section{Those involved in the workshop}

Bringing together medical staff, patient representatives and IT staff within the Hospital, the workshop was therefore an opportunity for a variety of stakeholders to help shape the design of an Electronic Patient Record system. In the event the dominant group within the workshop were the doctors and consultants: The workshop had been organised by a senior Consultant, and of the 9 core participants, 6 were doctors ranging from Junior to Consultant. Nurses were invited to participate, but none was available to attend because of staffing pressures. Also participating were one member of the Information Systems department in Hospital, and two representatives from the Patients and Carers Association. It is unsurprising, therefore, that the doctors became the dominant group in the workshop. The discussion became largely focused on doctors' clinical information and knowledge needs, and how they might make use of and interact with an Electronic Patient Record system.

\section{How a knowledge management system might help Hospital}

A key issue facing Hospital is the pressure to admit patients from MAU to the ward (or send them home) within a certain time limit. The same is also true of the Accident and Emergency (A\&E) department, with a shorter time limit. For the doctors and consultants in the process, there is particular pressure to reach a correct diagnosis - of patients arriving with no medical history - within that deadline. The process involves doctors making a 'differential diagnosis' - i.e. a list of probable conditions and their treatments - during which time they may need to draw upon a range of information and knowledge sources. These include the patients themselves and their observable symptoms, GP records, results of tests, opinions of 
colleagues, medical databases and published works from respected sources. Sources not immediately to hand have to be accessed separately, and it can be frustrating and timeconsuming waiting for paper-based records (e.g. doctors' records) to be delivered. Doctors are also under pressure to keep up with the ever-growing body of knowledge in medicine, which is becoming increasingly available online: As one doctor said, "in order to keep up you would have to be reading all day every day." This means that they have to consult a wide range of sources which are accessed separately in different forms, placing great strain upon their professional judgement. Doctors must decide whether to take the time to access a source that may not return any useful knowledge or information. However, as well as using knowledge and gathering information, the diagnosis also involves recording information, often in (albeit unintentionally) illegible handwriting. The current information system supporting the patient's progress from MAU to ward is therefore perceived by doctors to be unreliable and inefficient: In the words of one participant, "the trouble with the current system is that there isn't one."

When the discussion turned to what form their ideal system would take, participants conceived of an integrated Electronic Patient Record system, allowing both the recording of information about the patient (and generation of 'paperwork') and provision of access to all information and knowledge sources needed to make a (differential) diagnosis. This would include links to ICT-systems in GP surgeries, care pathways (e.g. physiotherapy, social services), and locally or nationally established NHS protocols. There would also be the capability in the system to display exactly what they need, rather than all the information a GP has on the patient, as well as helping them to identify the information they need to know. The system would provide support for decision making, both in drilling down the differential diagnosis and helping to record the decisions made. As this system would need to be mobile and give access to the Internet, it would necessarily be ICT-based, most probably via a laptop (this was considered a more practical 'diagnosis-centred' solution than another suggestion for the patient to carry a smart card). As one Consultant suggested, "the computer makes up for us not having a perfect memory."

\section{Users interacting with the system}

While the doctors discussed in detail what the system should be able to provide for them, and how they would like to access it, they had a less clear vision of who should be putting information into the system. Indeed, the question provoked a substantial discussion of the 
perceived barriers to such an ideal system working e.g. limited time for input, whether it is the role of doctors to type up records, cultural inertia in the implementation of new working practices. It was evident that the doctors perceived the benefits of an Electronic Patient Record would make it worthwhile for them to overcome the changes to their working practices. However, their reservations were perhaps more deeply rooted in the realisation that, if such a system is to work in the way they would like, then it is not just the responsibility of doctors to be putting information into the system: They are dependent upon other groups - e.g. nurses, GP surgeries - also to be inputting information, even though the doctors may be getting more out of the system than they themselves put in.

\section{Concluding comments}

In this case the requirements were clearly defined from the perspective of the doctor's needs. The participant from Hospital's IT department was keen to warn against doctors designing their own ideal system, as there were already a number of similar ICT-based initiatives (in areas like delivery of X-ray or test results) already in the pipeline. Furthermore, the patient representatives frequently reminded doctors of a role for the patient in providing information for the decision-making process. While it was clear that the doctors were conceiving first and foremost how the Electronic Patient Record would be of help to them in reaching a diagnosis, they did nevertheless stress the importance of linking the system with other initiatives in the NHS.

Subsequent to the workshop, a pilot system linking various databases using a vortal (virtual portal) interface has been developed and implemented for use in the MAU at Hospital.

\section{Case 2-Ambulance}

The background to the knowledge management system

The need to incorporate new ICT is equally pressing within Ambulance. For example, Ambulance is currently bidding for $£ 12$ million funding from central government to introduce new technologies with remote links between Ambulance management, central control, local stations and mobile crews. Ambulance also has a five year ICT Strategy overarching several interlinked projects, one of which - the Knowledge and Information Management (KIM) project - is concerned with how information in Ambulance is stored, made available and reported via the Intranet platform. According to the KIM Project Initiation Document, it aims to oversee the 'ongoing development of the Intranet,' together with the implementation of a 
'content management system' and an 'enterprise reporting tool,' while promoting the concept of the 'paperless office.'

\section{Positioning the workshop}

A key problem which the KIM project aims to address is the perception of 'information overload' in the service - of too much 'blanket' sending of information across the organisation, and not enough specific targeting of information to different groups. However, the project team is also keen for staff across the service to view knowledge and information needs as something they need to take a proactive part in defining for themselves. The project team had tried other ways of eliciting these needs, e.g. through the use of questionnaires, but these had achieved limited participation. Furthermore, the project is determined to promote the Intranet as a tool into which all staff proactively input information, and which is integrated into their normal working practices. It would also be intended to form a tool for knowledge management, not just information management, especially if the normal working base for the ambulance crews became the cab, rather than the ambulance station, as was intended. It was therefore decided to hold participative workshops with a cross-section of groups across the organisation.

\section{Those involved in the workshop}

A series of three, day-long workshops were run on successive days, including a total of 24 participants (6, 7 and 11 participants on each day). The intention was to include a crosssection of the entire organisation, in terms of:

- the level of the hierarchy, including all tiers from Executive Director to middle management to Ambulance Care Assistant;

- responsibilities, including centrally and locally-based staff from, patient facing divisions, the control room, fleet management, procurement, unions, and beyond;

- $\quad$ size of station;

- city/rural location of station;

- length of service;

- hospital and non-hospital based stations.

Since each participant in a given workshop had a different background, they could perhaps bring a unique perspective of the situation. This cross-section of the organisation also aimed to foster a sense of user involvement in the project, and define exactly what the different parties wanted to get out of Ambulance's ICT systems. 


\section{How a knowledge management system might help Ambulance}

This wide cross section in all three workshops made the outcomes highly eclectic in their representation of knowledge and information needs across the service. Nevertheless, each of the three workshops was similar in tone, and with similar overall views and discussions occurring. The workshop approach had sought to elicit the knowledge and information needs of participants, i.e. what knowledge informs their roles, a question which clearly involves knowing where they seek and how they access information. However, as there was a cross section of participants in each workshop, the participants were expressing a broad range of knowledge and information needs, thus giving only a general picture across the service. Discussions also became dominated by the perceived barriers to an ICT Strategy working indeed there was a pervasive preoccupation with the difficulties of implementing cultural change in the service, which many participants said they had witnessed over the years (it is important to remember that this is an organisation with a fairly mature workforce, and where long service is the norm). In the first two workshops, participants were grappling with what they were being required to do, and this is perhaps why the familiar territory of barriers to change gave them a tangible focus.

For the third workshop, the KIM project manager (who had not been participating in the workshops, but observing from a distance) intervened to provide the group with specific direction related to the project's needs. Precise questions posed to this workshop were 'what information should be communicated to you?' and 'how do you want the information communicated to you?' There was clearly an underlying view by the KIM project team that this was about defining the information which they, as managers, should be disseminating. This is also evident in the Project Initiation Document, which defines a set of 'Information Requirements of the Service' explicitly stating that they are 'from the perspective of providing sufficient information to support consistent decision-making and management control throughout the organisation.' The information they are talking about here is predominantly that which supports their highly command and control style of managing the organisation e.g. the provision of shift and holiday rosters, and the minutes of meetings.

The workshop group was comfortable with this, as it appeared feasible within the time, deciding for themselves that it would be most productive if they concentrated on the requirements of a specific group. They settled on the information requirements of mobile cab- 
based crews, which was something most participants felt they could contribute to, most having been out 'on the road' at some stage in their career. Their view of this focussed on the local operational needs of the crews - what they need in order to be able to perform their roles effectively. This varied from clinical advice such as "do not give Ms. ABC adrenaline" to staffing information and traffic details.

The issue was raised of a difference between information which crews may need to seek or 'pull in' for themselves, and information which needs to be provided from management. However, the focus was predominantly on information provided from management. As the human resources director at the third workshop pointed out, there is a lot about management 'doing it right', but no clear enunciation of what people believe should be the management's role in the provision of information.

Even though each workshop took a different route, the content of discussion in each was nevertheless focused on the requirements of organisational management and control. Nonmanagement participants were also viewing their requirements in terms of what managers should provide to them.

There was some discussion in the workshops about co-operating with other NHS organisations and groups. Participants in the first workshop talked about an ongoing project to share information directly with hospitals via remote terminals in A\&E departments.

Participants in the first two workshops specifically stressed the desirability of "electronic patient report forms" and the need for crews to have access to these, and help with making a diagnosis, from a mobile laptop. Also, one participant in the first workshop warned of the danger that KIM might not be able to "integrate with the NHS."

\section{Concluding comments}

In Ambulance, a particular type of requirement is knowledge and information about what people are doing -for managers, what the operational people are doing, and for the operational people, what managers want i.e. the operational knowledge and information requirements. This is knowledge which is easier to make explicit and thus put in an ICT system. The deeper more tacit knowledge (e.g. how to deal with a difficult patient) is more difficult to capture and disseminate. Indeed, it was observed that some knowledge which is at present circulated by word of mouth within an ambulance station could not be put into an ICT 
system because of the Data Protection Act. For example, "beware if you have to collect Mr. $\mathrm{XYZ}$; he is likely to swear and throw things at you".

\section{Analysis and discussion}

First it is important to note that both organisations are proposing ICT-based solutions to their knowledge and information management challenges, and that essentially these solutions are locally bounded. We concentrate on the local boundedness here; the issue of the extent to which ICT can actually provide such solutions is beyond the scope of this paper. The findings from both cases point to the importance of taking an holistic view of the emergency care process or 'care chain' and the role of knowledge management within it.

Through the cases we can identify six parties with quite different KM needs involved at different stages in the process of providing emergency care: (1) the ambulance crews that first attend to patients, the knowledge needs of which have been explored above; (2) ambulance control that, for example, provides traffic and vehicle management knowledge support to the ambulance crews; (3) GP surgeries that request ambulances for their patients, as well as providing emergency information to, and receiving information from, hospitals; (4) nurses in A\&E and MAU; (5) junior doctors in A\&E and MAU; and (6) consultants in A\&E and MAU. The knowledge needs of the last two parties have been explored above. However, the significant KM differences between junior doctors and consultants are of particular note. For example, a key decision for a junior doctor in A\&E or MAU facing a difficult diagnosis or treatment decision in the early hours of the morning is "should I wake my senior consultant on this one"? A KM system may help here.

At present, the question of KM in the emergency care process has been approached in a fragmented way and is viewed from the narrow perspective of the organisation itself. This is not a criticism of the way Ambulance and Hospital are developing their ICT systems and grappling with the importance of knowledge management. In the absence of a coherent view of the process, the organisations inevitably develop solutions in a fragmented way. In both case studies there is certainly a recognition that there are other players up and down the care chain which it makes sense to co-operate with (e.g. Hospital talked about exchanging information with GPs, Ambulance talked about sharing information with A\&E). However, as we shall go on to argue, as the participants in the chain essentially have an underlying view of 
information use which is locally bounded, their solutions to knowledge and information management challenges are bound to be local ones.

It is interesting how the cases differed in this respect, but nevertheless are illustrative of the same underlying approach. In the Ambulance case, questions about knowledge needed within the system, and the nature of the information which flows through it, are only viewed from the perspective of Ambulance. Furthermore there is a preoccupation in the discussion with information provision from management to Ambulance staff, and how an ICT system could be provided to support such a role. Staff generally overlook the importance and nature of what they may need to put onto such as system (which could have no immediate payoff for them), or how they should interact with the wider system. One exception to this was the desire of paramedics to use in-cab ICT to transmit a patient's cardiac rhythm to an A\&E doctor to get expert immediate advice on the most appropriate treatment for the patient. Nor in Ambulance is there any widespread realisation of knowledge and information which Ambulance staff need to 'pull' in for themselves in order to do their jobs - albeit paramedics are aware of the importance of getting drug dose information for babies. These are perhaps understandable in an organisation where the relationship between management and staff is oriented toward command and control-style management, unlike Hospital. Information flow is largely discussed from the perspective of structures for management and control of the organisation, hence the remote laptops which all Ambulance crews are to have is seen as a management device.

In Hospital, on the other hand, the need for a global Electronic Patient Record system is recognised, although it is approached from the perspective of how consultants can use the system to support their own local operational knowledge needs. Although there is a strong management tier in Hospital, this is very separate from the professional sanctity of the doctors and their application of clinical knowledge. Indeed, the pilot system in Hospital referred to above has been "programmed and delivered by clinical staff with no input or funding from managers". In the Hospital workshop, while the focus was on an Electronic Patient Record 'following' patients, the doctors were understandably scoping up its characteristics from the perspective of how they can use a system to gain the information and knowledge required to make a differential diagnosis. This is essentially the application of their professional knowledge, and a judgement for which often they alone will take responsibility. Their predominant perspective is of what they can pull in and use to support 
them in their decision making. However, the doctors were rarely talking in terms of how they could contribute to the Patient Record, but more often talked about such input as someone else's (often the nurse's) responsibility.

The cases therefore point to the importance of distinguishing between what might be called a) local and operational knowledge and b) global and clinical knowledge. Note that by knowledge we mean the knowledge which participants themselves have in this process, and information is what the participants interact with. The knowledge needs to be applied to the information. (Figure 2 illustrates examples of these differences for Ambulance)

\section{TAKE IN FIGURE 2 ABOUT HERE}

\section{a) Local and operational knowledge}

This is the knowledge and associated information which various groups involved in the emergency care process - e.g. ambulance control staff, paramedics, consultants - need and apply in their jobs. It can be viewed from the individual perspective of how they know what to do and how to act in the operational aspects of their work. For example, in Figure 2 we identify "stock control for drugs via the cab - just in time ordering" and "infection control, cleaning logs, equipment log numbers etc database in cab" as examples of operational knowledge which is only really needed locally by paramedics. For Hospital, examples include "potentially useful drug interactions" and "previous cases with similar symptoms" as examples of local, operational knowledge for doctors. Such needs, both for knowledge and supporting information, are by nature local and context-specific and vary enormously from group to group.

\section{b) Global and clinical knowledge}

This is knowledge and associated information which needs to flow along the emergency care process, which managers, doctors, nurses, ambulance staff and other health care professionals all play a part in contributing to, and which could perhaps be thought of as more generic to the system. In addition, where it is specific, it is specific to the patient rather than the staff or organisation. This might be thought of both as the accumulated clinical knowledge relating to the patient and his/her medical condition, and the perhaps more factual information about the patient such as who they are, where they live, next of kin etc. (such information may not all 
need to go on an Electronic Patient Record at all, but some may also be gained directly from the patient where possible).

Thus an Electronic Patient Record should contain the sum total of both information and knowledge which has accumulated thus far in the patient's journey through the emergency care chain - e.g. symptoms diagnosed, treatments already given. This is completely distinct from say, the bodies of knowledge a doctor may need to consult in reaching a diagnosis, or the information that control gives to the ambulance about where to take the patient. The latter example falls into the local, operational category. However, the former illustrates that information and knowledge about a specific patient is not all that needs to travel along the care chain. While traffic information and bed availability might be relatively local matters, the system would also benefit by sharing knowledge about making a diagnosis along the care chain.

Both Ambulance and Hospital see a need for local and operational information and knowledge management, and for global information management relating to the specific patient. However, there was no explicit recognition in any of the workshops of the need for any other knowledge to be shared or transferred along the emergency care process.

\section{Limitations of this work}

This paper is limited by only two organisations being studied. However, we have had good exposure to these organisations, both through the range of individuals involved in the workshops and through meetings before and after these workshops. We recognise that it is unwise to generalise from a sample of two, but in the absence of any other studies, anecdotal evidence is that both Hospital and Ambulance are typical. The work of Newell et $\mathrm{al}^{16}$ confirms the local boundedness of much NHS thinking about knowledge.

Earlier we identified six parties involved in the emergency care process that may have different KM needs. A wide cross-section of individuals from four of these parties have informed the development of the ideas presented in this paper. In the context of MAU and $A \& E$, where patients only remain for less than two days, we conjecture that the knowledge and information needs of the nurses may not be very different from those of the doctors. Noticeable, however, is the lack of any GP surgeries informing our proposal of a systems vision for emergency health care provision. The contribution of GP surgeries to this vision 
has been captured from all but the individuals in the GP surgeries. To explain, information is sometimes transferred between both the GP and ambulance crews (if the ambulance crew are responding to an emergency call by a GP) and the GP and A\&E/MAU (often in the form of patient up-dates from A\&E/MAU to GPs). We are unable to evaluate the implications of this with confidence. It might be that the perspective of the doctors in A\&E and MAU (who have most contact with GPs, and most similarity of background to them) satisfactorily represents GPs' current involvement. However, it also might be that the GPs want to take a more active role in emergency health provision, and that additional knowledge or integration into the process would facilitate this. GP surgeries increasingly use other types of health care worker, too. Further research is necessary, but we believe that a systems vision of emergency care is appropriate whatever the GPs' perspective.

\section{Conclusions}

Health care is one of many areas in which ICT-based knowledge management systems are suggested as offering potential benefits. In this research, we have studied the perceptions of some of the potential "customers" of knowledge management systems relating to emergency health care. These include both those who would be hands-on users of the systems (e.g. health care professionals) and their indirect beneficiaries (e.g. patients). The care of any one patient is likely to involve many different groups of staff across several organisations, for example ambulance crews, nurses and hospital doctors. Previous studies have tended to focus on a single organisation and/or on the providers of knowledge management systems rather than their users/beneficiaries.

Our findings are that on the whole the potential users have a good appreciation of the need for better knowledge management locally, and of the need to communicate with other groups involved in emergency care. However, they do not appear to have put these two together to realise the importance of knowledge management systems applying to the whole process: to be global rather than local.

The principal contribution of this paper is therefore to explore the complexity of knowledge management in the emergency care process, and to draw an important distinction between two types and applications of knowledge: local operational knowledge and global clinical knowledge. Viewing emergency care or the care chain as one complete process or system in which many organisations play a part, brings the focus of attention to the information and 
knowledge which needs to flow through this process. It also illustrates how different organisations and professions both interact with and add to the information as it snowballs with the patient. If we can identify the roles of the various participants, and how they interact with information and knowledge needed in the emergency care process, this will usefully inform the requirements of a process-wide ICT system.

Of course there is a need for local solutions to address the specific operational knowledge and information needs of the various groups involved in the emergency care process. It is also understandable, given funding and governance structures, that the organisations should be attempting separate local solutions to knowledge and information management challenges. However, the important question for these organisations is how these separate local systems in the process interact with the system carrying the patient information. The Electronic Patient Record cannot be constructed as the domain of the group or organisation, but something which they all need to incorporate into their local systems. However, there is a danger that the organisations involved continue to develop different systems which then become incompatible with the systems needed to support process-wide information flow and knowledge management.

Therefore, we are arguing for a different approach to the development of knowledge management systems and their supporting information systems, including an Electronic Patient Record-type system. This is an issue which clearly cannot be solved by Hospital or Ambulance alone. The potential users have a view of knowledge and information which is locally bound, and stems predominantly from the perspective of how they can use a system to support the application of their own local operational knowledge needs. The balance between local operational knowledge and global clinical knowledge needs to be addressed before an Electronic Patient Record system could properly function. In Hospital there is an evident willingness to share this 'global view' of the NHS (this was seen both in the doctors' workshop and the management workshop not drawn upon in this paper). However, it is hard for the organisations to do this, given that the process is so fragmentary, and it will require considerable change to make it possible. Considering the issue at Primary Care Trust level may help, but this still does not cover all six interacting parties identified above.

Taking the systems view even more broadly, considerations of knowledge management in emergency care should also not be separated from those relating to non-emergency care in the 
same organisations. This is an even larger task, and here the needs of other health care professionals may well diverge more from those of the doctors.

From the knowledge management standpoint, the following questions therefore need to be addressed in relation to any Electronic Patient Record system. In which health care processes will the Electronic Patient Record be used? Which organisations will need to use it, which groups of staff (professional and other) within them, and when? Which information relates only to local operational knowledge, and which to global clinical knowledge?

Only when these answers are known can the scope of an Electronic Patient Record system which in principle could range from an all-encompassing national system to one only applying for a single "episode" within a single hospital - be determined.

Knowledge management can then support the design and implementation of any system. Some of the questions which it would be able to address include: What are the user requirements of such a system regarding the input and output of information? How do operational staff use such a system across a variety of situations, for example, attending a patient on the $30^{\text {th }}$ floor of a high-rise building, in an Accident and Emergency department on a chaotic Saturday night, or during a very large-scale local/national emergency?

There are, therefore, many barriers to be overcome in providing better support for emergency health care. This paper helps by arguing for the importance of a systems vision for knowledge management in the NHS. Some of the barriers may be addressed by helping the NHS to view emergency care as a process necessitating the flow of patient-centred information and knowledge, to which all participants have a responsibility to contribute. Other barriers will require organisational, cultural and practical changes to be made, to enable all participants to play a full part in contributing to the ICT systems and use them to their maximum advantage. The relationship between managers, clinical and other NHS staff is an important element in this. It was very different in the two cases we have described. Much of this cultural change will need to focus on the willingness of participants to share their knowledge. However, it is clear that they are at present far from being able to exchange even information in the emergency care process, so it seems a long way away before all participants will be able to effectively share their knowledge along the chain for the ultimate benefit of the patient. 


\section{Acknowledgement}

The authors are grateful for the very helpful comments of two anonymous referees.

\section{References}

1. Fawcett SE and Cooper MB (2001). Process integration for competitive success: Benchmarking barriers and bridges. Benchmarking 8: 396-412.

2. Morash EA and Clinton SR (1998). Supply chain integration: Customer value through collaborative closeness versus operational excellence. Journal of Marketing Theory and Practice 6: 104-120.

3. Minnick A, Young WB, and Roberts MJ (1995). 2,000 patients relate their hospital experiences. Nursing Management 26: 25-31.

4. Newman K (1994). The Single Visit Clinic: A case study in process re-engineering. Business Change and Re-engineering 2: 10-18.

5. Bence V (1995). St. James's Hospital and Lucas Engineering Systems: a BPR collaboration. Business Change and Re-engineering 2: 30-39.

6. Arnott S (2003). National buying to slash NHS costs. Computing, 26 February.

7. Rubenstein-Montano B, Liebowitz J, Buchwalter J, McCaw D, Newman B, Rebeck $\mathrm{K}$, and The Knowledge Management Methodology Team (2001). A systems thinking framework for knowledge management. Decision Support Systems 31: 5-16.

8. Argyris C and Schön DA (1978). Organizational learning, a theory of action perspective. Addison-Wesley: Reading, Mass.

9. Cuthbertson C and Farrington J (2002). Methods for knowledge management strategy formulation: a case study. In: Coakes E, Willis D, and Clarke S (eds). Knowledge Management in the SocioTechnical World: The Graffiti Continues. Springer-Verlag: London. pp 139-152.

10. Ferrari FM, Fares CB, and Martinelli DP (2002). The systemic approach of SSM: The case of a Brazilian company. Systemic Practice and Action Research 15: 51-66.

11. Al-Karaghouli W, Fitzgerald G, and Alshawi S (2002). Knowledge Requirements Systems (KRS): An Approach to Improving and Understanding Requirements. In: Coakes E, Willis D, and Clarke S (eds). Knowledge Management in the Sociotechnical World: The Graffiti Continues. Springer-Verlag: London. pp 170-184.

12. Senge PM (1990). The fifth discipline, the art and practice of the learning organization. Doubleday: New York.

13. Coakes E, Willis D, and Clarke S, eds. (2002) Knowledge Management in the SocioTechnical World: The Graffiti Continues. Computer Supported Cooperative Work, ed. Diaper D and Sanger C., Springer Verlag: London.

14. Reuthe E and Allee V (1999). Knowledge management: Moving the care model from a "snapshot" to a "story". Health Forum Journal 42: 26-28.

15. Desouza KC (2002). Knowledge management in hospitals: A process oriented view and staged look at managerial issues. International Journal of Healthcare Technology \& Management 4: 478-497.

16. Newell S, Edelman L, Scarbrough H, Swan J, and Bresnen M (2003). 'Best practice' development and transfer in the NHS: the importance of process as well as product knowledge. Health Services Management Research 16: 1-12.

17. Checkland P and Scholes J (1990). Soft Systems Methodology in Action. John Wiley: Chichester.

18. Checkland P (1999). Systems Thinking, Systems Practice. John Wiley: Chichester. 
19. Checkland P and Holwell S (1998). Information, Systems and Information Systems making sense of the field. John Wiley: Chichester.

20. Lehaney B and Paul RJ (1996). The use of soft systems methodology in the development of a simulation of out-patient services at Watford General Hospital. Journal of the Operational Research Society 47: 864-870.

21. Lehaney B, Clarke SA, and Paul RJ (1999). A case of intervention in an outpatients department. Journal of the Operational Research Society 50: 877-891.

22. Batalden P and Splaine M (2002). What will it take to lead the continual improvement and innovation of health care in the twenty-first century? Quality Management in Health Care 11: 45-54.

23. Van Beveren J (2003). Does health care for knowledge management? Journal of Knowledge Management 7: 90-95.

24. Davenport TH and Glaser J (2002). Just-in-time-delivery comes to knowledge management. Harvard Business Review 80: 107-112.

25. Melymuka K (2002). Knowledge management helps cut errors by half. Computerworld, July 8, 2002 36: 44.

26. Pedersen MK and Larsen MH (2001). Distributed knowledge management based on product state models - the case of decision support in health care administration. Decision Support Systems 31: 139-158.

27. Ashburner L and Fitzgerald L (1996). Beleaguered professionals: clinicians and institutional change in the NHS. In: Scarbrough H (ed) The Management of Expertise. Macmillan Press: Houndmills. pp 190-216.

28. Hansen MT, Nohria N, and Tierney T (1999). What's your strategy for managing knowledge? Harvard Business Review 77: 106-116.

29. Carter B (2000). The expert's opinion: knowledge management. Journal of Database Management 11: 42-43.

30. Scarbrough H and Swan J (2001). Explaining the diffusion of knowledge management: the role of fashion. British Journal of Management 12: 3-12.

31. Earl M (2001). Knowledge management strategies: Toward a taxonomy. Journal of Management Information Systems 18: 215-233.

32. Alavi M and Leidner DE (2001). Review: Knowledge Management and Knowledge Management Systems: Conceptual Foundations and Research Issues. MIS Quarterly 25: 107-136.

33. Forgionne GA and Kohli R (1995). Integrated MSS effects: An empirical health care investigation. Information Processing \& Management 31: 879-896.

34. Slipy SM (1995). Boston hospital using seven telemedicine systems within facility. Health Management Technology 16: 34.

35. Moreno L, Aguilar RM, Pineiro JD, Estevez JI, Sigut JF, and Gonzalez C (2001). Using KADS methodology in a simulation assisted knowledge based system: application to hospital management. Expert Systems with Applications 20: 235-249.

36. Moseley L and Mead D (2001). Explaining the low penetration of decision support systems into clinical practice. Expert Update 3: 30-34.

37. Standridge CR and Steward D (2000). Using Expert Systems for Simulation Modeling of Patient Scheduling. Simulation 75: 148-156.

38. Eden C and Ackermann F (1989). Strategic Options Development and Analysis (SODA) - using a computer to help with the management of strategic vision. In: Doukidis GI, Land F, and Miller G (eds). Knowledge-based Management Support Systems. Ellis Horwood: Chichester. pp 198-207.

39. Eden C and Ackermann F (1998). Making Strategy: The Journey of Strategic Management. Sage: London. 
40. Roginski C (1995). Applying SODA in the NHS - A facilitator's story. OR Insight 8: 28-32.

41. Shaw D (forthcoming). Evaluating electronic brainstorms using new techniques to analyse the brainstormed ideas. Journal of the Operational Research Society.

42. Sosik JJ, Avolio BJ, and Kahai SS (1998). Inspiring Group Creativity - Comparing Anonymous and Identified Electronic Brainstorming. Small Group Research 29: 331.

43. Dennis AR, Haley BJ, and Vandenberg RJ, A meta-analysis of effectiveness, efficiency, and participant satisfaction in group support systems, in International Conference on Information Systems. 1996: Cleveland, Ohio.

44. Shaw D (2003). Evaluating electronic workshops through analysing the 'brainstormed' ideas. Journal of the Operational Research Society 54: 692-705.

45. Shaw D, Ackermann F, and Eden C (2003). Sharing knowledge in group problem structuring. Journal of the Operational Research Society 54: 936-948.

46. Edwards JS, Collier PM, and Shaw D, Management accounting and knowledge management. 2003, CIMA: London.

47. Scarbrough H (1996). Strategic IT in financial services: the social construction of strategic knowledge. In: Scarbrough $\mathrm{H}$ (ed) The management of expertise. Macmillan: Basingstoke. pp 150-173. 
List of Figure and Table captions

Figure 1 - An extract of a map from Hospital (to illustrate structure)

Figure 2 - An extract from a map from Ambulance (to illustrate local and global knowledge)

Table 1 - Notable stages in the research methodology 
Figure 1 - An extract of a map from Hospital (to illustrate structure)

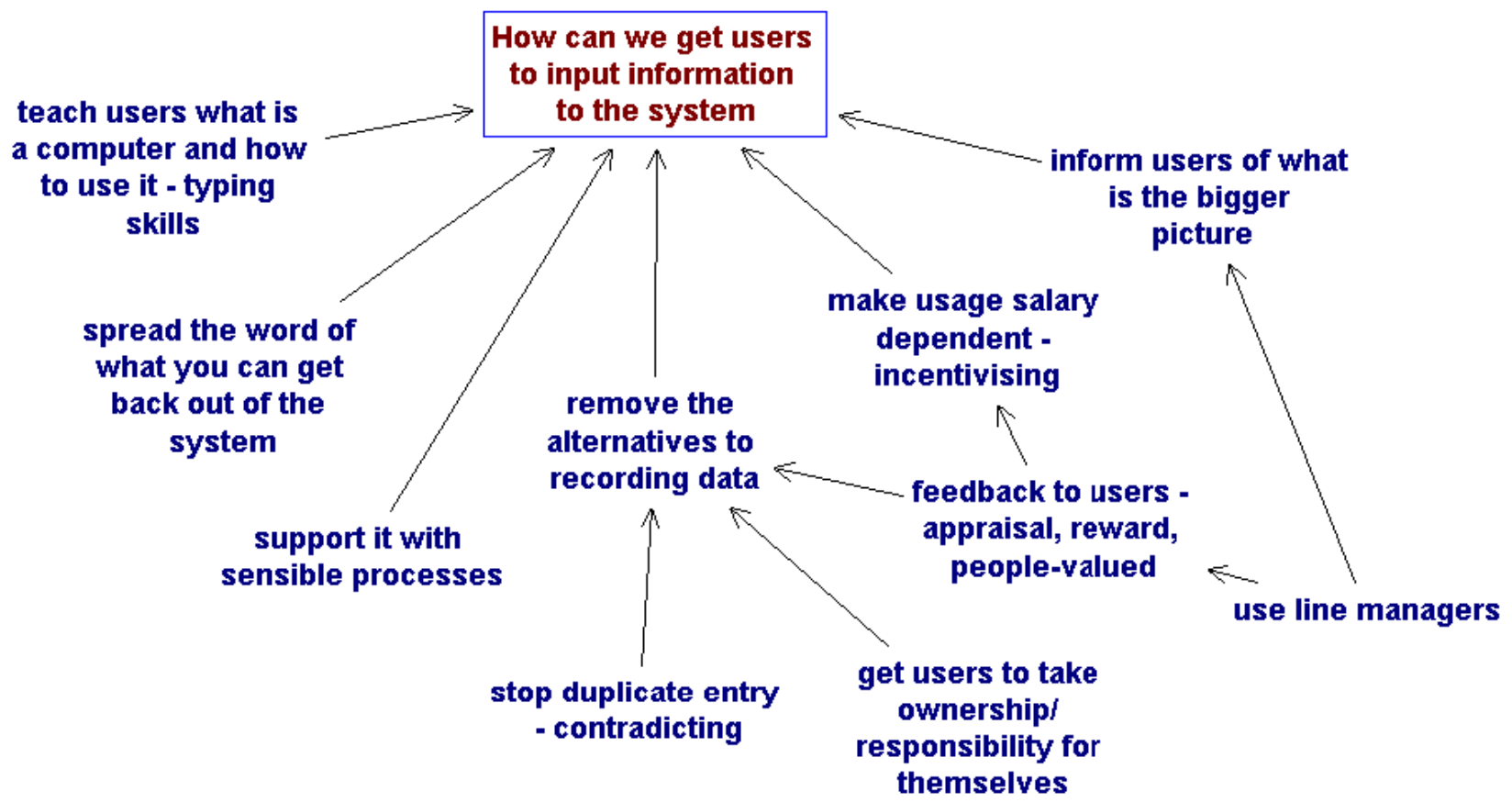


Figure 2 - An extract from a map from Ambulance (to illustrate local and global knowledge)

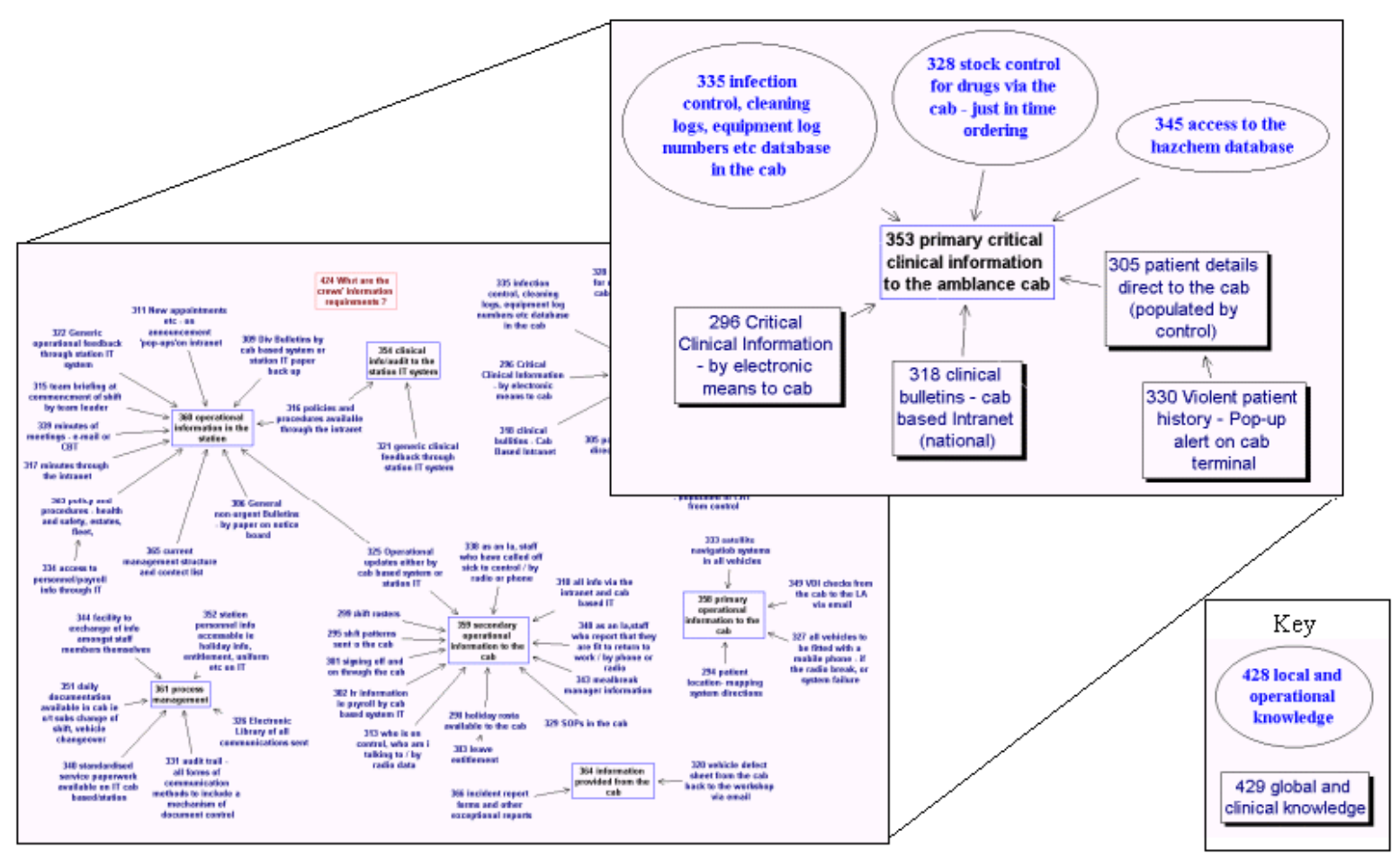


Table 1 - Notable stages in the research methodology

\begin{tabular}{|c|c|}
\hline Stage Description & Implication for research methodology. \\
\hline $\begin{array}{l}\text { Initiate contact with the client } \\
\text { organisation }\end{array}$ & $\begin{array}{l}\text { Self-selection of client organisation to participate in the } \\
\text { research following general invitation. }\end{array}$ \\
\hline $\begin{array}{l}\text { Pre-workshop discussion } \\
\text { with client organisation }\end{array}$ & $\begin{array}{l}\text { To gain insight on the background of KM in the organisation } \\
\text { and contextual workshop factors effecting the workshop eg } \\
\text { participants, location, culture etc. }\end{array}$ \\
\hline $\begin{array}{l}\text { Design and agreement of } \\
\text { workshop agenda (with the } \\
\text { client and then the } \\
\text { participants) }\end{array}$ & $\begin{array}{l}\text { To address the particular concerns of the client organisation, } \\
\text { and accounting for contextual factors. A validation of what } \\
\text { might be the important factors. }\end{array}$ \\
\hline The workshop & $\begin{array}{l}\text { An opportunity to collect data in the form of group built and } \\
\text { validated maps, researcher observations, facilitator insights, } \\
\text { participant-completed exit questionnaires. Also the directions } \\
\text { of the re-modelling of the flexible workshop agenda provided } \\
\text { insight to what was/was not important, and why. }\end{array}$ \\
\hline Client de-brief & $\begin{array}{l}\text { To gain immediate insight to the client's impression of the } \\
\text { topics discussed, concerns for the future, motivation to } \\
\text { pursue next steps and reaction to the workshop process. } \\
\text { Initial client validation of the data/process/direction. }\end{array}$ \\
\hline Post-workshop data analysis & $\begin{array}{l}\text { Analysis of all sources of data to feed into the final report } \\
\text { and identify directions for future collaboration. }\end{array}$ \\
\hline Workshop report & $\begin{array}{l}\text { To feedback to the participants and organisation the key } \\
\text { output/decisions from the workshop. Identification/invitation } \\
\text { to pursue further work. }\end{array}$ \\
\hline $\begin{array}{l}\text { Client/participant feedback } \\
\text { on report }\end{array}$ & Further validation of the key outcomes from the workshop. \\
\hline $\begin{array}{l}\text { Identification of generic and } \\
\text { specific KM themes. }\end{array}$ & $\begin{array}{l}\text { Synthesis of data and outcomes from the multiple workshops } \\
\text { to inform the development of KM theory, and workshop } \\
\text { practice. }\end{array}$ \\
\hline
\end{tabular}

